\title{
Leveling the Playing Field: Assessment of Gross Motor Skills in Low Socioeconomic Children to their Higher Socioeconomic Counterparts
}

\author{
Megan M. Adkins ${ }^{1 *}$, Matthew R. Bice' ${ }^{1}$, Danae Dinkel², John P. Rech ${ }^{1}$ \\ ${ }^{1}$ Kinesiology and Sport Science, University of Nebraska- Kearney, $25049^{\text {th }}$ Ave, Kearney, NE 68849, United States \\ ${ }^{2}$ Health and Physical Education, University of Nebraska- Omaha 6001 Dodge Street, Omaha, NE 68182, United States \\ Corresponding Author: Megan M. Adkins, E-mail: adkinsmm@unk.edu
}

\section{ARTICLE INFO}

Article history

Received: May 22, 2017

Accepted: July 07, 2017

Published: July 31, 2017

Volume: 5 Issue: 3

Conflicts of interest: None

Funding: None

\begin{abstract}
Background: Fundamental movements (FM) of children influence the willingness to engage in physical activity (PA). Thus, proper FM skills are the foundation for a lifespan of PA. Objective: This study examined what factors may affect children's PA in relation to FM pattern capabilities. Methods: The study examined the influence of SES when three low-income schools were provided additional PA opportunities on days PE was not taught. FM patterns in relation to object control (OC) and locomotor skill (LC) development were evaluated on $\mathrm{K}(\mathrm{n}=871), 1^{\text {st }}$ $(\mathrm{n}=893)$, and 2nd graders $(\mathrm{n}=829)$ using the Test of Gross Motor Development-2 (TGMD-2) instrument (Ulrich, 2000). Schools were dichotomized and categorized as being low SES $(\mathrm{n}=2008)$ and high SES $(\mathrm{n}=578)$ status. Results: A significant relationship was revealed with LC $(r=0.264 ; p=0.001)$, OC $(r=0.171 ; p=0.001)$, and total TGMD-2 $(r=0.264 ; p=0.001)$. Low and high SES schools significantly improved overall TGMD-2 scores. High SES schools children were significantly higher in LC $[\mathrm{F},(2,1272)=29.31, \mathrm{p}=0.001], \mathrm{OC}[\mathrm{F},(2,1272)=$ $23.14, p=0.001]$, and total TGMD-2 $[F,(1,1272)=38.11, p=0.001]$. Conclusion: Low SES schools need to concentrate on PA-based activities to engage students in FM patterns, to help narrow the gap in FM capabilities. In addition, the increase in PA opportunities for lower SES schools could positively impact brain function, cardiovascular fitness, and overall well-being.
\end{abstract}

Key words: Physical Education, TGMD, Fundamental Motor Skills, Low Socioeconomic Students

\section{INTRODUCTION}

According to the Centers for Disease Control (2010, 2013), children who meet the recommendation of 60 minutes of physical activity everyday have a lower chance of developing chronic diseases later in life and achieve greater levels of cardiorespiratory fitness and bone strength. Additionally, children who are physically active tend to have increased self-esteem, reduced levels of anxiety and depression, and show improved brain function, academic scores, and have better attendance rates in school (Tremblay, Inman, \& Williams, 2000; United States Department of Health and Human Services, 2016; Centers for Disease Control and Prevention, 2010; Strauss, Rodzilsky, Burack, \& Colin, 2001). Although the correlation between physical activity, health, and learning performances is widely supported in research, the lack of children meeting the physical activity recommendation of 60 minutes of daily moderate-to-vigorous physical activity is a global concern (Troiano et al., 2008; Guthord, Cowan, Autenrieth, Kann, \& Riley, 2010). Specifically within the United States, a report by the National Physical Activity Plan Alliance (NPAPA; 2016) found only one-fourth of children are currently meeting physical activity recommendations.
Due to this lack of physical activity, $75 \%$ of children are at an increased risk for future obesity, diabetes, and related chronic illness (NPAPA, 2016).

From birth, children develop movement skills through moving, balancing, stabilizing, and controlling their bodies. These elements of movement are crucial for the developmental progression of a child to successfully perform more complex physical tasks such as combined moves utilized in sports (shooting a lay-up in basketball) later in adolescents (Catenassi et al., 2007). Children with developed motor skills have a greater willingness and desire to engage in physical activity in comparison to children with poorer motor skill development (Wrotniak, Epstein, Dorn, Jones, \& Kondilis, 2006). Thus, proper fundamental movement skills are the foundation for a lifespan of physical activity. Having well-developed movement skills may greatly influence a person's level of desire and confidence to partake in physical activity later on in life (Gallahue \& Ozmun, 1998).

Decades of research have demonstrated numerous factors that can influence children's physical activity opportunities and relatedly fundamental movement skills. Some of these barriers emerge from issues such as safety of the neighbor- 
hood, parental perspective of the need for physical activity, and lack of transportation for children to and from physical activity opportunities (Centers for Disease Control and Prevention, 2003; Kerr et al., 2006; National Safe Routes Task Force, 2008). While disparities have been revealed in physical activity levels of children, little research has examined this potential in motor skills. Schools and Physical education classes are often seen as the time to develop motor skills but it is not known if increased time in school would help improve acquisition of motor skills (Centers for Disease Control and Prevention, 2010; Janz, Dawson, \& Mahoney, 2000; National Center for Chronic Disease Prevention and Health Promotion, Division of Adolescent and School Health, 2010). Researchers hypothesize additional time to practice during the school day will improve motor skill development of children.

The number of opportunities for children to participate in physical activity opportunities outside of school is growing daily, with new club and recreational teams being formed all over the United States. Both free play and vigorous physical activity participation rates are lower in children of low SES families (Hansen \& Chen, 2007; Inchley, 2005). However, research indicates before and after school time frames are when children are being less physically active (Smith, Hannon, Brusseau, Fu, Burns, 2016). Parents may arguably be the biggest influence on a child's involvement in behaviors due to their control over what activities their children partake in and what resources (i.e., money) are available that allow for participation to occur (Welk, Wood, \& Morss, 2003). Children from low-income families have significant key barriers such as the cost of the recreation program, and lack of support from home due to transportation issues, which may hinder them from being a part of recreational activities outside of school (Canadian Fitness and Lifestyle Research Institute, 2015).

Students are in school seven to eight hours a day, thus the school environment can be another influential factor in physical activity levels of children. The majority of this time is in a sedentary environment in the regular classroom. Within schools, there are numerous barriers to physical activity promotion and implementation, but they do differ by school level, experience of the specialist teachers, and can be teacher or student-related (Jenkinson \& Benson, 2010). Physical activity can also be influenced by the overall school facility provisions (e.g., amount of facilities available) and equipment (e.g., loose equipment, balls) used during recess (Ridgers, Salmon, Parrish, Stanley, \& Okely, 2012).

Physical education is looked upon as a class that can enhance a child's fundamental movement skill development and knowledge of sports and activities as well as be a major contributor to the accumulation of physical activity (Society of Health and Physical Educators of America (SHAPE, 2014). Changes have occurred in the last 25 years making many schools reduce or eliminate recess and Physical education (SHAPE of the Nation, 2016). However, students who attend higher SES schools continue to receive a better quality Physical education experience and spend more time participating in Physical Education (Sallis, Zakarian, Hov- ell, \& Hofstetter, 1996). This is concerning as involvement in complex activities during Physical Education courses aid in the development and improvement of fundamental movement skills (SHAPE of the Nation, 2010). Further, regardless of SES, children who participate in Physical education have better coordination and biomechanics allowing them to perform complex activities required in physical activities (Ketelhut, Bittmann, \& Ketelhut, 2003). According to Fairclough and Stratton (2005), children with higher developed movement patterns engaged in more physical activity during Physical education lessons.

One evaluation piece used in Physical education to determine fundamental movement proficiency levels is the Test of Gross Motor Development, second version (TGMD-2). This test scores a child in grades Kindergarten-2nd grade (K-2) on their ability to perform fundamental movement skills, such as running, jumping, throwing, skipping, and catching, that require the use of large muscle groups (Gallahue \& Ozmun, 1998; Wrotniak et al., 2006). Since the development of these skills are positively associated with physical activity, and inversely associated with sedentary behaviors and obesity it is critical to evaluate children's movement skills at an early age to ensure lifelong physical activity habits (Khalaj \& Amri, 2013; Wrotniak et al., 2006). Unfortunately, low SES children may be at a disadvantage due to decreased opportunities for physical activity outside of school and receiving less Physical education time during school. Given the disparity between what has been established in the literature about the significant role of physical activity for children, the declining number of children meeting the recommended physical activity levels, and the need for developed fundamental movement skills; this study aims to examine what factors may affect children's physical activity in relation to fundamental movement pattern capabilities. Specifically, the current manuscript attempts to answer the following questions.

Does socioeconomic status (SES) level influence fundamental movement patterns of children?

Does additional fundamental movement skill practice time during the school day improve overall fundamental movement abilities for low socio-economic children in grades $\mathrm{K}-2$ ?

\section{METHOD}

\section{Participant}

In 2011, public schools within one school district in central Nebraska were notified of the opportunity for their students in grades K-2 to be tested on fundamental movement patterns using the TGMD-2 assessment. Three low socio - economic Title I schools, defined as having a school population with a poverty level (determined by free and reduced meal counts) $40 \%$ or above free and reduced lunch, which is an indicator of poverty level, selected to participate (United States Department of Education, 2013). Two high socio economic schools, defined as having a school population with a poverty level (determined by free and reduced meal counts) between $0 \%-14.9 \%$ also agreed to participate 
(United States Department of Education, 2013). All schools within the district had comparable gymnasium spaces and Physical Education teachers who had been in the field for more than five years. Socio-economic status is the measure of influence that the social environment has on individuals, families, communities, and schools. The definitions of SES emphasize that, as a construct, (a) it is conditional, (b) it is imposed on people, (c) it is used for comparisons, and (d) it is based on economics, opportunity, and means of influence. The SES levels per school were defined by the Nebraska Department of Education in the Handbook for Continuous Improvement in Nebraska Schools (2012). Title I schools are defined as having student enrollment of at least 40 percent of children from low- income families. Title 1 is designed to help students served by the program to achieve proficiency on challenging state academic achievement standards. Schools receive funds from the Federal government to operate "school wide programs" to upgrade the instructional program for the entire school (United States Department of Education, 2017).

\section{Instrument}

Trained research assistants conducted the TGMD-2 assessments at all of the participating schools located in central Nebraska during Physical education class in the Fall (2011), and Spring (2012). Training of the assistants included a professional development taught by professors from a local University to learn about the various assessment pieces and then practice assessments on children from the local preschool. During 2012-2014 school years the low SES schools $(n=3)$ were the only schools that elected to continue with TGMD-2 testing of their students. Prior to beginning testing at the school sites the local University conducting the research received IRB approval. For consistency and accuracy, the TGMD-2 protocol manual, which provides specific instructions to conduct each of the TGMD-2 assessment components, was used by the research assistants to standardize procedures and for quality assurance.

The TGMD-2 has been shown and established as a valid and reliable measure to assess fundamental movement patterns of children (Ulrich, 2000). The TGMD-2 includes six locomotor (run, gallop, hop, leap, horizontal jump, slide) and six object-control (striking a stationary ball, stationary dribble, kick, catch, overhand throw, underhand roll) skills. Participants performed each skill three times. Each skill includes several movement components. If the participant performed all movement components correctly they received a score of 1 ; if they performed any component incorrectly they received a score of 0 . This procedure was completed for each of the trials, and scores were summed to obtain a total raw skill score. Raw skill scores were then added to obtain a raw locomotor subtest score and a raw object-control subtest score. Inter-rater reliability $(89 \%$ agreement rate) was established by all at the same time by assessors practicing the assessments with children at a local pre-school before movement skills were assessed at the elementary schools.

\section{Intervention}

After the fall (2011) TGMD-2 data collection, all three low SES schools, received the traditional Physical education class two times a week, similar to the other schools but on days the children did not have Physical education, each K-2 class received a twenty minute structured physical activity time, taught by a senior level Physical Education major student from the local University. During the physical activity time the K-2 students played low organized games, which require minimal explanation, that emphasized the fundamental movement patterns found in the TGMD-2 test manual. The physical activity instructors were provided access to the research based physical activity curriculum SPARKÒ, for ideas for class physical activities. SPARK ${ }^{\circledR}$ has been identified as a national model for programs designed to increase physical activity and includes a variety of activities designed to improve student physical activity and movement skills (Partnership \& Prevention, 2008). For example, the game "junk yard" is a game where students work on overhand or underhand throwing patterns and throw the "junk" to the other side of the gym to "clean" up their half side of the basketball court that is cluttered by bean bags that are thrown by the opposing team on the opposite side of the basketball court. The University Physical education major followed an outline of the class time provided by the lead researcher for the physical activity time at the three schools. The outline included the following for the $20 \mathrm{~min}-$ ute time frame: (a) three minute warm-up incorporating the fundamental movement patterns, (b) two and a half minute introduction to the activity and reminder of proper skill execution, (c) thirteen minutes of playing the physical activity of the day (focusing on at least two fundamental movements), and (d) one and a half minute closure. The three low SES elementary schools continued the physical activity portion for K-2 along with regularly scheduled Physical education in their school day for three years (2011-2014). The TGMD-2 data were assessed every Fall and Spring during those years (2011-2014). The high SES schools, whom did not receive the additional physical activity time elected to only have the TGMD-2 testing completed in the Fall, 2011 and Spring, 2012 school year. This was due to lack of interest from Physical Educators and the concern of the amount of time needed to complete the TGMD-2 test during Physical education class without receiving the benefit of the additional physical activity class like the low SES schools received.

\section{Statistical Analysis}

Descriptive statistics were analyzed per student frequencies in each grade (Kindergarten, $1^{\text {st }}$, and $2^{\text {nd }}$ grade). Pearson product correlations were used to analyze associations between school SES and TGMD-2 (Locomotor, Object Control, and total TGMD). A univariate analyses were used to examine TGMD change and direction between the Fall and Spring among each of the different schools and adjoining years. Low SES schools A, B, and C was analyzed for Year 1, 2, and 3. No data exists for Schools D and E for 2012-2014; 
therefore, only Year 1 could be analyzed. Further, multivariate analyses assessed rating of TGMD between low and high SES schools. Data were deemed significance at 0.05 .

\section{RESULTS}

\section{School Demographics}

A total of 2,586 scores of elementary aged students were used in data analysis. Schools were dichotomized and categorized as being low SES $(\mathrm{n}=2008)$ and high SES $(\mathrm{n}=578)$ status. Further the sample includes a range of students that included kindergarten $(\mathrm{n}=871), 1$ st grade $(\mathrm{n}=893)$, and 2 nd grade $(\mathrm{n}=829)($ See Table 1$)$.

\section{Movement Skills and SES Level}

Table 2 describes the relationship between TGMD and SES. TGMD data were only available during Year 1 for high SES schools. A significant relationship was revealed with the construct locomotor $(r=0.264 ; \mathrm{p}=0.001)$, object control $(\mathrm{r}=0.171 ; \mathrm{p}=0.001)$, and total TGMD $(\mathrm{r}=0.264$; $\mathrm{p}=0.001)$. The positive relationship suggests students with high SES yield higher ratings of TGMD.

A multivariate analysis revealed that during Year 1, students that attended high SES schools had significantly higher ratings of locomotor skills $[\mathrm{F},(2,1272)=29.31, \mathrm{p}=0.001]$, object control $[\mathrm{F},(2,1272)=23.14, p=0.001]$, thus yielding significantly higher total TGMD $[\mathrm{F},(1,1272)=38.11$, $\mathrm{p}=0.001]$ (See Table 3).

Table 1. School demographics

\begin{tabular}{|c|c|c|c|c|c|c|}
\hline & \multicolumn{3}{|c|}{ High SES } & \multicolumn{2}{|c|}{ Low SES } & \multirow{2}{*}{$\begin{array}{l}\begin{array}{l}\text { Total } \\
\text { amount }\end{array} \\
\text { A-E } \\
\end{array}$} \\
\hline & $\mathbf{A}$ & B & $\mathrm{C}$ & D & $\mathbf{E}$ & \\
\hline Kindergartens & 674 & 680 & 661 & 248 & 323 & 2586 \\
\hline $1^{\text {st }}$ graders & 248 & 245 & 220 & 93 & 65 & 871 \\
\hline $2^{\text {nd }}$ graders & 209 & 233 & 214 & 83 & 154 & 893 \\
\hline Total amount $=\mathrm{n}$ & 217 & 202 & 227 & 72 & 111 & 829 \\
\hline
\end{tabular}

Table 2. Correlations between TGMD and SES

\begin{tabular}{lccc}
\hline TGMD-2 sub categories & \multicolumn{3}{c}{ SES } \\
\cline { 2 - 4 } & $\mathbf{n}$ & $\mathbf{r}$ & $\mathbf{p}$ \\
\hline Locomotor & 2586 & 0.264 & 0.001 \\
Object control & 2586 & 0.171 & 0.001 \\
Total TGMD & 2586 & 0.264 & 0.001 \\
\hline
\end{tabular}

*Denotes significance at $\mathrm{P}<.01$

\section{Impact of Additional Movement Skill Practice}

ANOVA was performed to analyze change in ratings of locomotor, object control, and overall TGMD. Table 4 provides the mean scores for the TGMD-2 in relation to locomotor, object control, and overall score for each school. The low SES schools completed the TGMD-2 analysis after the first year of data collection to determine if TGMD-2 scores improved with additional physical activity opportunities to practice the fundamental movement skills. Analysis revealed that both low and high SES schools significantly improved overall TGMD (See Table 4).

\section{DISCUSSION}

The primary purpose of this study was to assess the motor proficiency (TGMD-2) of children in grades K-2 attending low and high SES schools. The secondary purpose of the study was to subsequently compare changes in motor proficiency of children at low SES schools when 20 minutes of physical activity were added on days Physical Education was not offered at the schools. To our knowledge this is the first study to assess the motor proficiency changes of $\mathrm{K}-2$ grade children when provided a structured physical activity time on days Physical Education was not offered. Overall, findings demonstrated that in year 1, (2011-2012) children at the higher SES schools scored higher than all low SES schools when completing the TGMD-2 both in the Fall and in the Spring. This would be expected due to research indicating higher quality of Physical education and more involvement in external physical activity opportunities outside of the school day (Center for Disease Control and Prevention, 2017). These findings coincide with previous research findings worldwide that typically have found that higher SES children score better on assessments related to fundamental or gross motor skills because of a combination of additional practice time, resources, and outside opportunities that students of high SES school children have compared to low SES schools (Hardy, King, Espinel, Okely, \& Bauman, 2010).

Interestingly, low SES schools consistently increased fundamental movement pattern scores between the fall and spring during year 1, 2, and 3 (2011-2014). However, students who attended high SES schools were still at a significant higher proficiency rate in regards to fundamental movement patterns when tested with the TGMD-2. These results provide evidence that physical activity programs emphasizing fundamental movement patterns, along with Physical education, should be implemented, but additional opportunities are still needed outside of school to improve fundamental movement pattern levels for children at low SES schools to meet the level of movement patterns of chil-

Table 3. Analysis of variance of TGMD-2: motor skills among low and high SES schools during Year 1

\begin{tabular}{|c|c|c|c|c|c|c|c|c|}
\hline \multirow[t]{2}{*}{ TGMD-2 sub categories } & \multicolumn{3}{|c|}{ Low SES } & \multicolumn{3}{|c|}{ High SES } & \multirow[t]{2}{*}{$\mathbf{F}$} & \multirow[t]{2}{*}{$\mathbf{p}$} \\
\hline & $\mathbf{n}$ & M & SD & $\mathbf{n}$ & $\mathbf{M}$ & SD & & \\
\hline Locomotor & 703 & 3.56 & 1.71 & 571 & 4.08 & 1.73 & 29.313 & 0.000 \\
\hline Object control & 703 & 2.39 & 1.29 & 571 & 2.76 & 1.38 & 23.14 & 0.000 \\
\hline Overall & 703 & 5.96 & 6.84 & 571 & 6.35 & 2.58 & 38.11 & 0.000 \\
\hline
\end{tabular}


Table 4. Analysis of change between fall and spring among Year 1, 2 and 3

\begin{tabular}{|c|c|c|c|c|c|c|c|c|}
\hline & & & \multicolumn{2}{|c|}{ Low SES } & \multicolumn{2}{|c|}{ Year 2} & \multicolumn{2}{|c|}{ Year 3} \\
\hline & & & M & $\mathbf{p}$ & M & $\mathbf{p}$ & M & $\mathbf{p}$ \\
\hline \multicolumn{9}{|l|}{ Low SES } \\
\hline \multirow[t]{6}{*}{ School A } & Locomotor & Fall & 2.844 & 0.001 & 0.811 & 0.000 & 2.000 & 0.000 \\
\hline & & Spring & 3.394 & & 2.396 & & 3.916 & \\
\hline & Object control & Fall & 2.293 & 0.419 & 1.273 & 0.000 & 1.546 & 0.000 \\
\hline & & Spring & 2.156 & & 2.207 & & 2.444 & \\
\hline & Overall & Fall & 5.137 & 0.11 & 2.084 & 0.000 & 3.546 & 0.000 \\
\hline & & Spring & 5.55 & & 4.603 & & 6.361 & \\
\hline \multirow[t]{6}{*}{ School B } & Locomotor & Fall & 2.720 & 0.000 & 1.250 & 0.000 & 1.972 & 0.000 \\
\hline & & Spring & 5.300 & & 4.310 & & 4.065 & \\
\hline & Object control & Fall & 2.090 & 0.000 & 1.857 & 0.009 & 1.906 & 0.000 \\
\hline & & Spring & 3.000 & & 2.367 & & 2.607 & \\
\hline & Overall & Fall & 4.820 & 0.000 & 3.112 & 0.000 & 3.875 & 0.000 \\
\hline & & Spring & 8.300 & & 6.680 & & 6.672 & \\
\hline \multirow[t]{6}{*}{ School C } & Locomotor & Fall & 2.778 & 0.000 & 0.960 & 0.000 & 1.477 & 0.000 \\
\hline & & Spring & 4.053 & & 3.465 & & 3.697 & \\
\hline & Object control & Fall & 2.256 & 0.160 & 1.376 & 0.000 & 1.688 & 0.000 \\
\hline & & Spring & 2.490 & & 2.613 & & 2.513 & \\
\hline & Overall & Fall & 5.035 & 0.000 & 2.336 & 0.000 & 3.165 & 0.000 \\
\hline & & Spring & 6.548 & & 6.079 & & 6.211 & \\
\hline \multicolumn{9}{|l|}{ High SES } \\
\hline \multirow[t]{6}{*}{ School D } & Locomotor & Fall & 4.795 & 0.010 & & & & \\
\hline & & Spring & 5.278 & & & & & \\
\hline & Object control & Fall & 2.549 & 0.000 & & & & \\
\hline & & Spring & 3.440 & & & & & \\
\hline & Overall & Fall & 7.344 & 0.000 & & & & \\
\hline & & Spring & 8.721 & & & & & \\
\hline \multirow[t]{6}{*}{ School E } & Locomotor & Fall & 2.730 & 0.000 & & & & \\
\hline & & Spring & 4.000 & & & & & \\
\hline & Object control & Fall & 2.323 & 0.002 & & & & \\
\hline & & Spring & 2.810 & & & & & \\
\hline & Overall & Fall & 5.055 & 0.000 & & & & \\
\hline & & Spring & 6.816 & & & & & \\
\hline
\end{tabular}

dren from higher SES schools. While the direct relationship between the proficiency of fundamental movement patterns and level of participation in physical activity remains inconclusive, the need for future research to determine perceived relationships of physical activity in children's ability to access a range of movement experiences still needs to be explored (Jaakkola \& Washington, 2013; Lai et al., 2014). Low SES schools could provide additional opportunities to their students to improve fundamental movement patterns by incorporating classroom activity breaks, before or after school physical activity programs, or creating cross-curricular activities during the school day. For instance, in science class, students could learn about biomechanics and practice the various fundamental movement patterns. Physical Educators could be utilized to educate classroom teachers in physical activities they could incorporate into their current teaching curriculum.

The current study has a number of strengths including the number of years of testing at the low SES schools, the relatively large sample size, the standard additional amount of time of 20 minutes provided to all low SES schools, and the use of a qualitative, valid assessment of fundamental movements. Limitations of the study should be noted. The assessment of the fundamental movement patterns were only as- 
sessed in the high SES status schools during year one 2011. Although the same core curriculum, SPARKOे was taught by all Physical education and University majors teaching physical activity class physical activity teachers in the district assessed, activities and development of specific components of the curriculum were not regulated. In addition, the University Physical education majors teaching the classes at the low SES schools had free reign over activities the teacher incorporated as long as the activity incorporated at least two fundamental movements. The fundamental movement patterns selected may not have been the areas in which the students needed to focus to improve their TGMD-2 score. Due to the design of this study a cause-and-effect relationship between physical activity and fundamental movement patterns cannot be concluded but only inferred.

\section{CONCLUSION}

The current findings suggest that schools, especially lower SES schools, need to concentrate on additional opportunities for physical activity-based activities to engage students in fundamental movement patterns throughout the school day. This could be accomplished through short classroom activity breaks conducted by classroom teachers, by adding a before or after school physical activity program, and/or if available, a program similar to the one outlined in this article where a physical activity class was added in the school day. By adding additional physical activity time, not only could the fundamental movement patterns improve, but brain function and cardiovascular fitness would potentially improve as well. Resources, personnel knowledgeable, and school administration may play into the success of the incorporation of the physical activity time. Overall, by providing physical activity and motor development opportunities for children, whether it is housed during school hours or after school, can be beneficial to helping improve all motor functioning and development of all children, regardless of SES.

\section{REFERENCES}

Canadian Fitness and Lifestyle Research Institute, Participation. (2015). The influence of socio-demographic factors on children's physical activity and sport. [Online] Available http://www.cflri.ca/sites/default/files/ node/1397/files/RF EN March 2015 final.pdf.

Catenassi, F. Z., Marques, I., Bastos, C. B., Basso, L., Ronque, E. R. V., \& Gerage, A. M. (2007). Relationship between body mass index and gross motor skill in four to six year-old children. Revista Brasileira de Medicina do Esporte, 13, 227-230. doi:10.1590/S151786922007000400003

Center for Disease Control and Prevention. (2017). Components of the whole school, whole community, whole child (WSCC). [Online] Available https://www.cdc.gov/ healthyschools/wscc/components.htm.

Centers for Disease Control and Prevention. (2010). Childhood obesity and overweight. [Online] Available http:// www.cdc.gov/obesity/childhood/
Centers for Disease Control and Prevention. (2013). Youth Risk Behavior Surveillance-United States, 2013. MMWR 2014;63 (SS-4).

Centers for Disease Control and Prevention. (2010). The Association Between School-Based Physical Activity, Including Physical Education, and Academic Performance. Atlanta, GA: U.S. Department of Health and Human Services, 2010.

Centers for Disease Control and Prevention (2008). Make a difference at your school. [Online] Available http://www. cdc.gov/HealthyYouth/KeyStrategies/pdf/make-a-difference.pdf.

Centers for Disease Control and Prevention. (2003). Physical activity levels among children aged 9-13 yearsUnited States, 2002. Morbidity and Mortality Weekly Report, 52, 785-788.

Fairclough, S., \& Stratton, G. (2005). Physical activity levels in middle and high school physical education: A review. Pediatric Exercise Science, 17(3), 217-236. doi:10.1123/pes.17.3.217

Gallahue, D. L., \& Ozmun, J. C. (1998). Understanding motor development: Infants, children, adolescents, adults. New York, NY: McGraw-Hill Humanities, Social Sciences \& World Languages.

Guthold, R., Cowan, M. J., Autenrieth, C. S., Kann, L., \& Riley, L. M. (2010). Physical activity and sedentary behavior among school children: A 34-country comparison. The Journal of Pediatrics, 157, 43-49. doi:10.1016/j. jpeds.2010.01.019

Hanson, M. D., \& Chen, E. (2007). Socioeconomic status and health behaviors in adolescence: A review of the literature. Journal of Behavioral Medicine, 30, 263-285. doi:10.1007/s10865-007-9098-3

Hardy, L., King, L., Espinel, P., Okely, A., \& Bauman, A. (2011). Methods of the NSW schools physical activity and nutrition survey 2010 (SPANS 2010). Journal of Science and Medicine in Sport, 14, 390-396. doi:10.1016/j. jsams.2011.03.003

Inchley, J. C. (2005). Persistent socio-demographic differences in physical activity among Scottish schoolchildren 1990-2002. The European Journal of Public Health, 15, 386-388. doi:10.1093/eurpub/cki084

Jaakkola, T., \& Washington, T. (2013). The relationship between fundamental movement skills and self-reported physical activities during Finnish junior high school. Physical Education and Sport Pedagogy, 18(5), 492-505.

Janz, K. F., Dawson, J. D., \& Mahoney, L. T. (2000). Tracking physical fitness and physical activity from childhood to adolescence: The muscatine study. Medicine \& Science in Sports \& Exercise, 32, 1250-1257.

Jenkinson, K. A., \& Benson A. C. (201). Barriers to providing physical education and physical education and physical activity in victorian state secondary schools. Australian Journal of Teacher Education, 35, 1-17.

Katzmarzyk, P. T., Denstel, K. D., Beals, K., Bolling, C., Wright, C., Crouter, S. E., \& Sisson, S. B. (2016). Results from the United States of America's 2016 report card on physical activity for children and youth. Jour- 
nal of Physical Activity and Health, 13, S307-S313. doi:10.1123/jpah.2016-0321

Ketelhut, K., Bittmann, F., \& Ketelhut, R. G. (2003). Relationship between motor skills and social status in early childhood. Medicine \& Science in Sports \& Exercise, 35, 179. doi:10.1097/00005768-200305001-00993

Kerr, J., Rosenberg, D., Sallis, J. F., Saelens, B. E., Frank, L. D., \& Conway, T. L. (2006). Active commuting to school: Associations with environment and parental concerns. Medicine \& Science in Sports \& Exercise, 38, 787-794. doi:10.1249/01.mss.0000210208.63565.73

Khalaj, N., \& Amri, S. (2013). Mastery of gross motor skills in preschool and early elementary school obese children. Early Child Development and Care, 184, 795-802. doi:10.1080/03004430.2013.820724

Lai, S. K., Costigan, S. A., Morgan, P. J., Lubans, D. R., Stodden, D. F., Salmon, J., \& Barnett, L. M. (2013). Do school-based interventions focusing on physical activity, fitness, or fundamental movement skill competency produce a sustained impact in these outcomes in children and adolescents? A systematic review of follow-up studies. Sports Medicine, 44, 67-79. doi:10.1007/s40279-013-0099-9

Morley, D., Till, K., Ogilvie, P., \& Turner, G. (2015). Influences of gender and socioeconomic status on the motor proficiency of children in the UK. Human Movement Science, 44, 150-156. doi:10.1016/j.humov.2015.08.022

National Physical Activity Plan Alliance. (2016). 2016 United States report card on physical activity for children and youth. [Online] Available http://www.physicalactivityplan.org/projects/reportcard.html.

National Safe Routes Task Force. (2008). Safe routes to school: A transportation legacy. A national strategy to increase safety and physical activity among American youth. [Online] Available http://www.saferoutesinfo. org/sites/default/files/task_force_report.web_.pdf

Nebraska Department of Education (2012). A handbook for continuous improvement in Nebraska schools: Equity and diversity focus. [Online] Available https://www.education.ne.gov/.

Partnership for Prevention. (2008). School-based physical education: Working with schools to increase physical activity among children and adolescents in physical education classes - an action guide. The community health promotion handbook: Action guides to improve community health. Washington, DC: Partnership for Prevention.

Ridgers, N. D., Salmon, J., Parrish, A., Stanley, R. M. \& Okely, A. D. (2012). Physical activity during school recess: A systematic review. American Journal of Preventive Medicine, 43, 320-328. doi:10.1016/j.amepre.2012.05.019.

Sallis, J. F., Zakarian, J. M., Hovell, M. F., \& Hofstetter, C. (1996). Ethnic, socioeconomic, and sex differences in physical activity among adolescents. Journal of Clinical Epidemiology, 49, 125-134. doi:10.1016/08954356(95)00514-5

Smith, C., Hannon, J., Brusseau, T., Fu, Y., Burns, R. (2016). Physical Activity Behavior Patterns during School Leisure Time in Children. International Journal of Kinesiology and Sport Science, 4(1), 17-25.

Society of Health and Physical Educators of America. (2014). National standards \& grade- level outcomes for K-12 physical education. Human Kinetics. Champaign, IL.

Society of Health and Physical Educators of America. (2010,16). Shape of the nation report: Status of physical education in the USA. [Online] Available https://www. shapeamerica.org/shapeofthenation 